\title{
Survey of non-invasive ventilation (NIPPV) in patients with acute exacerbations of chronic obstructive pulmonary disease (COPD) in the UK
}

\author{
M J Doherty, M A Greenstone
}

\begin{abstract}
Background-Non-invasive positive pressure ventilation (NIPPV) has been shown to be beneficial in the treatment of acute exacerbations of chronic obstructive pulmonary disease (COPD) complicated by respiratory failure. A survey was undertaken to assess the availability of NIPPV for the treatment of acute exacerbations of COPD and to determine how NIPPV is delivered in hospitals in the UK. Methods-A questionnaire was sent to consultants with an interest in respiratory medicine from 268 of the hospitals found in the BTS directory. The questionnaire enquired about the hospital as well as the availability of NIPPV in the hospital. If NIPPV was available in the hospital, details of implementation, staffing and funding were determined.
\end{abstract}

Results-Replies to the questionnaire were received from $98.5 \%$ of consultants. NIPPV was available in $48 \%$ of hospitals, these hospitals tending to serve larger populations and to have more respiratory physicians than the hospitals where NIPPV was not available. There was considerable regional variation in the availability of NIPPV. In hospitals where NIPPV was not available the reason(s) were lack of consultant training in $53 \%$, lack of other staff training in $63 \%$, financial in $63 \%$, and doubt about the benefit of NIPPV in $15 \%$ of cases. In those hospitals where NIPPV was available, clinical practice varied greatly: $68 \%$ of centres treated fewer than 20 patients a year with this form of treatment and $9 \%$ treated more than 60 patients a year. Although NIPPV was paid for completely from the trust equipment budget in 46 hospitals (41\%), other money such as research or charitable funds were used at least partially in the other hospitals and NIPPV was financed solely from research or charitable funds in 41 hospitals (37\%).

Conclusions-Equipment for NIPPV is available in less than half of the acute hospitals in the UK. In those in which it is available it is generally underused. Lack of training and problems with funding are generally given for the failure to introduce NIPPV.

(Thorax 1998;53:863-866)

Keywords: non-invasive positive pressure ventilation; chronic obstructive pulmonary disease; hospital; survey
Patients with acute exacerbations of chronic obstructive pulmonary disease (COPD) are prone to developing acute respiratory failure and this respiratory acidosis is associated with a poor prognosis. ${ }^{1}$ When ventilatory failure develops intubation and mechanical ventilation on an intensive therapy unit (ITU) can be life saving by improving gas exchange and resting the respiratory muscles. However, ITU care is expensive and there is limited bed availability. Intubation itself can be associated with life threatening complications including nosocomial ventilator associated pneumonia. These problems have led to the use of non-invasive positive pressure ventilation (NIPPV), a technique previously used in the treatment of the hypoventilation associated with neuromuscular and chest wall disorders, as a way of trying to avoid intubation.

The benefit of NIPPV over conventional treatment in selected patients with respiratory failure associated with acute exacerbations of COPD has been shown in randomised controlled trials. ${ }^{2-4}$ The benefits shown in these studies have included improved arterial blood gas tensions, decreased breathlessness, and reductions in the need for intubation, mortality and length of hospital stay. Only one randomised controlled study has failed to show a benefit from NIPPV 5 and this study was small.

These results have led to a recommendation that equipment for NIPPV should be available in all hospitals that admit patients with acute respiratory failure caused by COPD. ${ }^{6}$ This recommendation, and the uncertainty as to which criteria should be used to select patients for NIPPV, led us to study the current practice in the UK. This was performed with special reference to the availability and usage of NIPPV and to the criteria used to select patients for this treatment.

\section{Methods}

We identified 268 hospitals with an in-post consultant respiratory physician or a general physician with an interest in respiratory medicine from the 272 hospitals found in the British Thoracic Society directory. ${ }^{8}$ A questionnaire was sent to one of the physicians in each hospital, a reminder questionnaire was sent 2-3 months later to all non-responders, and non-responders were further followed up by a telephone interview. The survey took place between March and August of 1997.

The questionnaire enquired about the number of respiratory physicians at the hospital, the estimated annual number of admissions 
Table 1 Answers to survey questions concerning care of patients receiving NIPPV for acute exacerbations of COPD

\begin{tabular}{lc}
\hline & No. of centres (\%) \\
\hline (1) Who makes the decision re initiating non-invasive ventilation? & \\
Respiratory physician & $80(66 \%)$ \\
Anaesthetist & $4(3 \%)$ \\
Other (please specify) & $7(6 \%)$ \\
$\quad$ Combination & $30(25 \%)$ \\
(2) Who sets up non-invasive ventilation? & $18(15 \%)$ \\
Nurse & $11(9 \%)$ \\
Physiotherapist & $40(33 \%)$ \\
Doctor & $49(41 \%)$ \\
Combination & $20(16 \%)$ \\
(3) Where is non-invasive ventilation initiated? & $30(24 \%)$ \\
General ward & $15(12 \%)$ \\
Respiratory ward & $16(13 \%)$ \\
HDU & $42(34 \%)$ \\
ITU & \\
Combination & $46(41 \%)$ \\
(4) If you have NIPPV in your hospital, how was it purchased? & $41(37 \%)$ \\
Trust equipment budget & $25(22 \%)$ \\
Research or charitable funds & \\
Both & $67(62 \%)$ \\
(5) If you do not use or have easy access to NIPPV, why is this? & $56(52 \%)$ \\
Financial & $67(62 \%)$ \\
Lack of experience with this form of treatment & $16(15 \%)$ \\
Lack of other staff with experience with this treatment & \\
Doubt about the benefit of this treatment & \\
\hline
\end{tabular}

with COPD, and the population covered by the hospital (these last two could be given as the actual number or as falling into one of a number of categories). Information on the use of NIPPV was sought including availability in the hospital or in a hospital to which patients could be transferred. If NIPPV was not available the reason(s) for this were determined. In those centres in which NIPPV was available the number of patients treated in this way annually and the criteria used to select these patients was asked. Further questions were designed to study how the NIPPV service was set up in the hospital-for example, who decided to initiate it, who delivered this form of treatment in practice, where NIPPV was performed and with what equipment. Data are presented for both the national and regional picture. Differences between those hospitals with and without NIPPV were analysed using the $\chi^{2}$ test for categorical data and the Mann-Whitney U test for continuous data. Copies of the questionnaire are available from the authors.

\section{Results}

Information either in the form of a returned questionnaire $(96 \%)$ or from information received in a telephone conversation was received from 264 of the 268 hospitals surveyed $(98.5 \%)$. Not all questions were completed in every case, so the number of replies varied for each question. Non-invasive positive pressure ventilation was available in $126(48 \%)$ of the hospitals and patients were able to be transferred to another hospital for this treatment in another $18(7 \%)$ cases. Hospitals where NIPPV was available served a significantly larger mean (SD) population (291 $(130) \times 10^{3}$ versus $230(110) \times 10^{3}, \mathrm{p}<0.05, \chi^{2}$ test) and had more respiratory physicians $(2.4$ (1.9) versus $1.4(0.7), \mathrm{p}<0.005)$ than those hospitals in which it was not available. They did not, however, treat more patients with exacerbations of COPD(481 (258) versus 471 (237), p >0.05, $\chi^{2}$ test). Hospitals where
NIPPV was available were more likely to be capable of initiating continuous positive airway pressure (CPAP) treatment in patients with obstructive sleep apnoea (73 of 113 versus 44 of $130, \mathrm{p}<0.001$ ).

There was great variation between regions in the proportion of hospitals in which NIPPV was available, from $17 \%$ of hospitals in Wales to $78 \%$ of hospitals in the South West region.

The criteria used to select patients varied with a number of blood gas criteria commonly being used. From the 126 responses received $21 \%$ used criteria similar to that of Confalonieri et $\mathrm{al}^{8}\left(\mathrm{pH}<7.33\right.$ and/or $\mathrm{PaCO}_{2}>7.18 \mathrm{kPa}$ and/or $\left.\mathrm{PaO}_{2}<7.98 \mathrm{kPa}\right), 13 \%$ used criteria similar to that of Bott et al $\left(\mathrm{PaCO}_{2}>6 \mathrm{kPa}\right.$ and $\mathrm{PaO}_{2}<7.5 \mathrm{kPa}$ ), whilst $22 \%$ used criteria similar to that of Kramer et $a l^{4}(\mathrm{pH}<7.35$ and $\mathrm{PaCO}_{2}>6 \mathrm{kPa}$ ). Another $24 \%$ used other arterial blood gas criteria including greater degrees of respiratory acidosis and a rising $\mathrm{PaCO}_{2}$ with a normal $\mathrm{pH}$ despite conventional treatment. About $20 \%$ of centres used clinical guidelines to select patients for treatment with NIPPV and these included exhaustion and failure to improve on standard treatment.

Many different models of machines were used. One hundred and sixteen centres answered the question on the type of machine used; $62(53 \%)$ used a single type of machine which was a pressure cycled machine in the majority of cases (92\%). In the 54 centres where more than one type of machine was used, $29(54 \%)$ had a volume cycled machine as well as a pressure cycled machine, and the remaining centres used two or more types of pressure cycled machines. Thus, of the 116 centres that answered this question, 111 had pressure cycled machines available and 34 had volume cycled machines.

Of those hospitals in which NIPPV was available, $51(42 \%)$ treated fewer than 10 patients annually, $32(26 \%)$ treated 10-20 patients each year, $21(17 \%)$ treated $20-40$ patients a year, seven (6\%) treated 40-60 patients a year, eight (7\%) treated 60-100 patients a year, and two hospitals, both tertiary referral centres for non-invasive ventilation in chronic respiratory failure, treated more than 100 patients annually. The 10 hospitals that treated more than 60 patients annually with NIPPV were significantly larger, in terms of estimated catchment area, than those that did not (375 000 versus $216000, \mathrm{p}<0.001$ ). The replies to the other questions are presented in table 1.

\section{Conclusions}

This study set out to assess the availability and use of a major new treatment for a common and life threatening disease. The fact that we achieved an almost $100 \%$ response rate with relatively few reminders reflects the great amount of interest in this form of treatment by UK respiratory physicians.

Non-randomised trials, randomised trials, ${ }^{2-4}$ and expert opinion ${ }^{6}$ all suggest a place for NIPPV in the treatment of respiratory failure associated with COPD with only a few dissenters. $^{59}$ Although publication bias in 
favour of positive trials may play a part in this, most respiratory physicians in the UK seem to agree with the evidence in favour as only $15 \%$ of those without access to NIPPV expressed doubt about the benefit of the treatment when specifically asked ( $7 \%$ of all centres). In spite of physicians' acceptance of the evidence, less than $50 \%$ of centres had equipment available on site and, although $7 \%$ had the capacity to transfer patients to another hospital for treatment, this is suboptimal practice.

Hospitals in which NIPPV is available tend to cover a larger population and to have more respiratory physicians, perhaps reflecting the ability of physicians in these hospitals to subspecialise. Regional variation in the availability of NIPPV was great, with it being more readily available around London and in the south, these being the areas in which the UK randomised trial took place. ${ }^{2}$ This variation might also arise because of staffing or financial differences between regions but it does not reflect regional variation in standardised mortality from COPD, which is lowest in the south. ${ }^{10}$

The survey suggests that the reasons for non-implementation of NIPPV are equally lack of training of health professionals in this form of treatment and financial. Problems with financing are underlined by the finding that funding for NIPPV often came from research or charitable funds. An awareness that this treatment can lead to a reduction in intubation and ITU utilisation might be a powerful argument in persuading trusts and purchasers that it is a worthwhile investment, although it is acknowledged that there are no hard data on the cost effectiveness of this approach.

This treatment is often started by medical staff, though commonly also by nursing staff and physiotherapists. Given recent changes in junior doctors' hours, it is unlikely that most units will be able to provide 24 hour cover by doctors fully trained in the use of this treatment. Hence nurses or physiotherapists will probably become more important in the delivery of this service. The survey did not enquire if a 24 hour service was available in each centre or how this was achieved. NIPPV often takes place in the general or respiratory wards (46\%), reflecting the shortage of ITU and high dependancy beds in the UK. It must be pointed out that the controlled studies which showed benefit from NIPPV were performed in ITUs or HDUs, with the exception of the study by Bott et al. ${ }^{2}$ This may well be important as some have suggested that NIPPV requires a high nursing input ${ }^{11}$ and so may not be as successful in less well staffed units.

Most centres used pressure support ventilation rather than volume support, though there is no difference in their efficacy. ${ }^{12}$ The popularity of pressure support may therefore reflect the fact that pressure cycled equipment is usually cheaper, easier to use, and more comfortable for the patient than volume cycled machines. ${ }^{13}$

It is unclear which criteria best select patients likely to benefit from NIPPV but it is clear that, as criteria used to select patients vary, so will the resulting workload. Although the commonest set of criteria were a $\mathrm{pH}$ of $<7.35$ and a $\mathrm{PaCO}_{2}$ of $>6 \mathrm{kPa}$, there was great variation between centres. Many commented that other factors were important in deciding who would receive NIPPV, such as the availability of trained nursing and medical staff capable of initiating the treatment at the time a particular patient was admitted to hospital. This problem with lack of comprehensive cover with trained staff might also explain the relatively low number of patients treated in many centres $(68 \%$ of centres treating fewer than 20 patients a year), whilst only $9 \%$ of the hospitals with NIPPV treated more than 60 patients a year. Data suggest that large numbers of patients might be eligible for this treatment; as approximately $20 \%$ of patients with an acute exacerbation of COPD are acidotic, ${ }^{1}$ an average district general hospital might expect to admit up to 80 acidotic patients annually. Each centre intubated and formally ventilated an average of 20 patients a year, there being no difference between centres with and without NIPPV. If NIPPV is indeed preventing intubation, this suggests that hospitals with NIPPV are generally more aggressive in treating ventilatory failure.

Of necessity, this survey could only give information relevant to a fixed point in time, even though changes may be planned for the future. To highlight this, 79 out of 128 hospitals had plans (or at least aspirations) to introduce NIPPV in the next two years, though in many cases this was conditional on either funding or staffing. Other problems are that the data were collected retrospectively and answers to many questions often had to be approximate as accurate data were not always available to the respondent. Some questions tried to categorise descriptive information which might not easily fit the answers allowed, though this made the questionnaire easier to complete, thereby helping to achieve the exceptional response rate.

In summary, this survey shows that NIPPV is available in just under half of hospitals and many hospitals use the equipment only irregularly. The main reasons for underimplementation are to do with training and finance rather than a perception of a lack of benefit. How NIPPV is implemented varies greatly between hospitals and this reflects not only variation in resources but also doubt about how and when NIPPV should be initiated. There is now sufficient evidence to justify this form of treatment in hospitals that admit patients with ventilatory failure so resources, in terms of equipment and training, should be made available. Given the recent increase in acute hospital admissions and financial constraints on provision of ward staff, the human resource implications, selection criteria, and ideal venue for initiating such treatment remain to be established.

1 Jeffrey AA, Warren PM, Flenley DC. Acute hypercapnic respiratory failure in patients with chronic obstructive lung respiratory failure in patients with chronic obstructive lung
disease: risk factors and use of guidelines for management. Thorax 1992;47:34-40. 
2 Bott J, Carroll MP, Conway JH, et al. Randomised controlled trial of nasal ventilation in acute ventilatory failure due to chronic obstructive airways disease. Lancet 1993;341: 1555-7.

3 Brochard L, Mancebo J, Wysocki M, et al. Non-invasive ventilation for acute exacerbations of chronic obstructive pulmonary disease. $N$ Engl f Med 1995;333:817-22.

4 Kramer N, Meyer TJ, Meharg J, et al. Randomised prospective trial of noninvasive positive pressure ventilation in tive trial of noninvasive positive pressure ventilation in acute respiratory fail

5 Barbe F, Togores B, Rubi M, et al. Noninvasive ventilatory support does not facilitate recovery from acute respiratory failure in chronic obstructive pulmonary disease. Eur Respir f 1996;9:1240-5.

6 Wedzicha JA. Noninvasive ventilation for exacerbations of respiratory failure in chronic obstructive pulmonary disease. Thorax 1996;51(Suppl 2):S35-9.

7 Hawkins R, ed. Directory of training posts and services in respiratory medicine. A Hawker Directory, 1997/8.
8 Confalonieri M, Parigi P, Scartabellati A, et al. Non-invasive mechanical ventilation improves the immediate and long term outcome of COPD patients wit

9 Foglio C, Vitacca M, Quadri A, et al. Acute exacerbations in severe COLD patients. Treatment using positive pressure ventilation by nasal mask. Chest 1992;101:1533-8.

10 Office of Populations Censuses and Surveys. Table 3, Series DH5 No 19, 1992 11 Chevrolet JC, Joliet $\mathrm{P}$, Abajo B, et al. Nasal positive pressure
ventilation in patients with acute respiratory failure: difficult and time consuming procedure for nurses. Chest 1991;100:775-82.

12 Meecham Jones DJ, Paul EA, Clarke GC, et al. Nasal ventilation in acute exacerbations of chronic obstructive pulmonary disease: effect of ventilator mode on arterial blood gas tensions. Thorax 1994;49:1222-4.

13 Schonhofer B, Sonneborn M, Haidl P, et al. Comparison of two different modes for non-invasive mechanical ventilatwo different modes for non-invasive mechanical ventila-
tion in chronic respiratory failure: volume versus pressure controlled device. Eur Respir f 1997;10:184-91. 